\title{
THE ABNORMAL QUIET DAYS IN SQ (H) IN MID AND LOW LATITUDES REGIONS
}

\author{
F. N. Okeke \\ Department of Plysics \& Astronomy. Unir ersity of Nigeria. Nsukka
}

\begin{abstract}
From the analysis and study of abnormal quiet days (AQDs) at mid and low latitudes locations, it was found that there is difference between the characteristics of phase variability $\mathrm{Sa}(\mathrm{H})$ of the low latitude locations. This suggests that the origin and cause of $A Q D s$ are of different sources in the two latitude regions. The AQDs events are independent of local time and could be of extra-terrestrial origin." The lunar contribution as seen from the analysis carried out has insignificant effects on the AQDs in both latitudes.
\end{abstract}

\section{INTRODUCTION}

Brown and Williams [1] introduced the concept of $A Q D$ s and Brown [2.3] expanded it. AQDs have also been defined as dars on which the diurnal maximum of $\mathrm{H}$ occurred outside the time interval of 0930-1230 hr LT [1.t]. Butcher [5] and Brown [6.7] also investigated the nature and the causes of AQD evènts. Brown and Butcher [8] also investigated the features in 'relation to its application to the prediction of the forthcoming sunspot maximum. Last et al. Sastri [9] also carried out some studies on AQDs in a low latitude region. Sastri [10] carried out similar work to that of Brown and Williains [1] using data of equatorial stations showing that the morphology of AQDs at these latitudes are distinctly different from that of mid-latitudes. Ther concluded that the difference in the characteristics of the phase variability of $\mathrm{Sq}$ $(\mathrm{H})$ between equatorial and mid-latitudes locations suggests that the origin of the AQDs is different in the two regions. In this paper. it is of interest to inquire whether there is any difference in the characteristics of the phase variation between midlatitude and low latitude locations. It is also important to investigate if there is significant contribution due to lunar effect.

\section{DATA ANALYSIS}

The published hourly values of $\mathrm{H}$. recorded at the Tesino geomagnetic obsenatory in 1992 [geomag. lat. $46.2^{\circ} \mathrm{N}$. geo. long. $11.7^{\circ}$ and at geomag. lat $46: 5^{\circ} \mathrm{N}$ geomag. long. $93.5^{\circ} \mathrm{l}$ and at Alibag [geo. lat. $18.63^{\circ} \mathrm{N}$. geo. long. $72.87^{\circ}$ and geonag. lat. $9.5^{\circ} \mathrm{N}$ and geomag. long. $\left.143.6^{\circ} \mathrm{E}\right]$ were used as the mid and tow latitude locations respectively. The mean hourly values of $\mathrm{H}$ were evaluated for all the months of the vear for all the international chosen quiet daris. Since these H values contain contributions from both solar quiet. daily variations due to lunar effects were filtered out using the Fourier series analysis of each daily rariation. after [10]. The resultant variation left is due mainly to the solar quiet daily rariation in $\mathrm{Sq}$ (H).
The horizontal component of the solar quiet daily variation at the station is expressed in the Fourier series as follows:

$$
\begin{aligned}
& f(t)=a_{0}+a_{1} \cos \omega t+b_{1} \sin \omega t+\ldots a_{3} \cos \omega t \\
& +b_{3} \sin \omega t+a_{+} \cos \omega t+b_{+} \sin \omega t
\end{aligned}
$$

where $a_{0} \cdot a_{n}$ and $b_{n}$ are defined in equation (2) and $n$ runs from 1 to $t$ in determining the harmonic coefficients $a_{1}, a_{2}, a_{3}, a_{4}$, and $b_{1}$. $b_{2} \cdot b_{3} \cdot b_{4}$

$a_{i j}=\frac{1}{24} \sum_{i=1}^{i+4} H(t)$

$a_{n}=\frac{1}{12} \sum_{t=1}^{24} H(t) \cos n \omega t$

$b_{n}=\frac{1}{12} \sum_{t=1}^{24} H(t) \sin n \omega t$

The published hourly values of $\mathrm{H}$ from one to twenty-four are used. Then by applying the Fourier series. the values of $f(t) \mathrm{H}$ were obtained for the mid and low latitude stations.

From the definition of $A Q D s$ according to [1.4]. these are days on which the diurnal maximum of $\mathrm{H}$ occurred outside the time interval $0930-1230 \mathrm{hr} \mathrm{L} T$. This paper is using this definition of $A Q D S$ :

The AQDs occurred in the months of August on the 14 th and 17 th dar between $15-20 \mathrm{hr}$ LT and 15-16The AQDs occurred in the months of August on the 14th and 17th day between 15-20 hr LT and 15-16 hr LT respectively in the low latitude region (see Table 1). It also occurred in the months of September and December on the 5th between 1516 hr LT and on the 28th and 29th day of 


\section{DISCUSSION}

The AQDs occurred in the months of August on the 14th and 17th day between 15-20 hr LT and 15-16 $\mathrm{hr}$ LT respectively in the low latitude region (see Table 1). It also occurred in the months of September and December on the 5th between 15-16 $\mathrm{hr} L \mathrm{~T}$ and on the 28th and 29th day of December between 02-05 hr LT and $05 \mathrm{hr} \mathrm{LT}$ respectively.

On the other hand, in the mid-latitude stations in almost all the months, the AQDs occurred between $20 \mathrm{hr}$ LT and $02 \mathrm{hr}$ LT. Except for the month of December where there is no clearly defined diurnal maximum of $\mathrm{H}$ outside the time interval of 0930-1230 hr LT (Table 2). There is clear evidence of difference in the characteristics of the phase variability of $\mathrm{Sq}(\mathrm{H})$, between the midand low latitude regions. They are somewhat out of phase. Finally it is clear that the lunar contribution has no significant effect on the AQDs variation.

\section{CONCLUSION}

The local time variation and spatial extent of the difference between the mid-latitude and low latitude stations suggests that the origin of AQDs is of different sources in the two latitude regions. AQDs event is independent of local time and should be of extra-terrestrial origin. The contribution due to lunar effect is not significant.

\section{Acknowledgements}

The author is very grateful to the Director of the Tesino Geomagnetic Observatory for supplying the data used in this study. The author also wishes to thank Prof. C. A. Onwumechi for his useful suggestions.

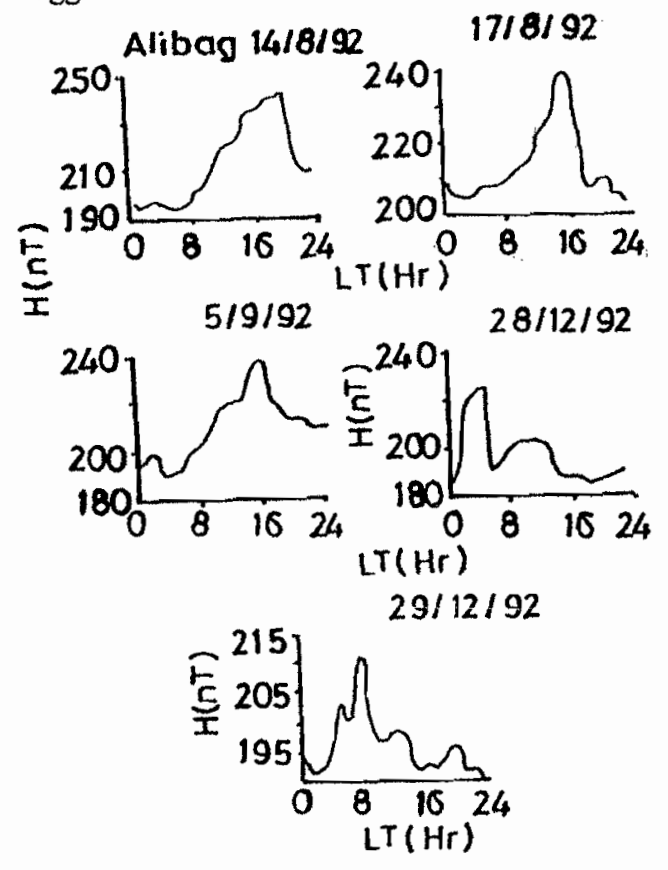

Fig.l: Abnormal quiet days variations of $\mathrm{H}$ for lowlatitude station 1992

\section{REFERENCES}

1. Brown, G. M. and Williams, W. R. (1969): Some properties of day-to-day variability of $\mathrm{Sq}(\mathrm{H})$, Planet. Space Sci. Vol. 17, pp 455-470.

2. Brown, G. M. (1974): A new solarterrestrial relationship, Nature, Vol. 251, pp 592-594.

3. Brown, G. M. (1975): Sq variability and aeronomic structure, J. Atmos. Terr. Phys., Vol. 37, pp 107-117.

4. Sastri, J. H. (1982): Phase variability of $\mathrm{Sq}(\mathrm{H})$ on normal quiet days in equatorial electrojet region, Geophys. J. R. Astr. Soc. Vol. 71, pp 187-197.

5. Butcher, E. C. (1982): An investigation on the causes of abnormal quiet days in $\mathrm{Sq}(\mathrm{H})$, Geophys. J. R. Astr. Soc. Vol. 69, pp 101-106.

6. Brown, G. M. (1981): The nature of abnormal quiet days in $\mathrm{Sq}(\mathrm{H})$, Geophys. J. R. Astr. Soc. Vol. 64, pp 513-521.

7. Brown, G. M. (1986): The change in $\mathrm{Sq}(\mathrm{H})$ amplitude on abnormal quiet days, Geophys. J. R. Astr. Soc. Vol. 86, pp 467473.

8. Brown, G. M. and Butcher, E. C. (1981): The use of abnormal quiet days in $\mathrm{Sq}(\mathrm{H})$ for predicting the magnitude of sunspot maximum at the time of preceding sunspot minimum, Planet. Space Sci. Vol. 29, pp 73-77.

9. Last, B. J. Emilia, D. A. and Outred, A. K. (1976): AQD occurrence at Addis Abba, Trivandrum and Alibag, Planet. Space Sci. Vol. 24, pp 567-571.

10. Chapman, S. and Bartels, J. (1940): Geomagnetism, Claredon Press, Oxford.
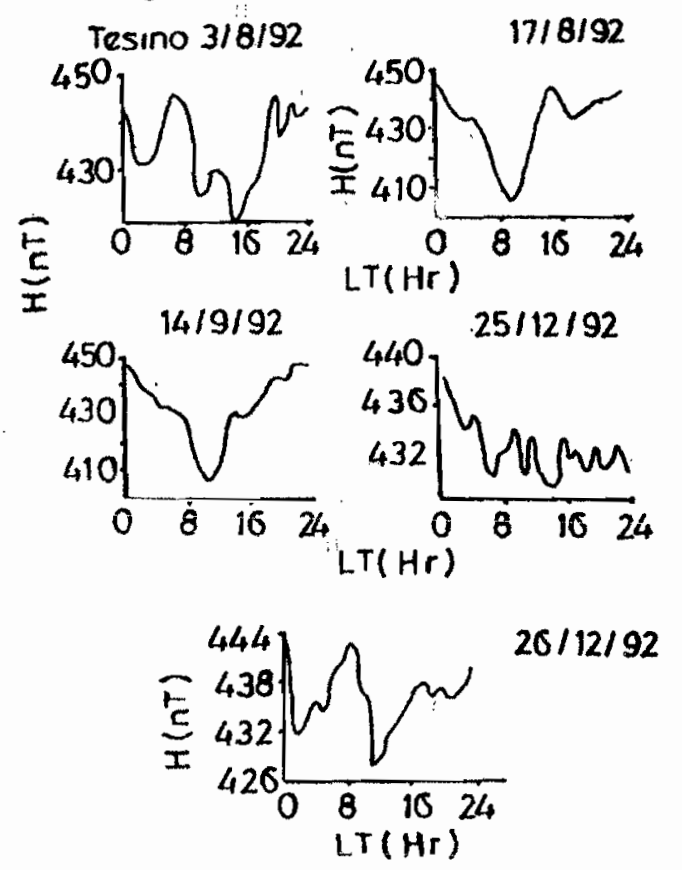

Fig.2: Abnormal quiet days variations of $\mathrm{H}$ for mid-latitude station 1992 